\title{
The effect of pneumoperitoneum and Trendelenburg position on respiratory mechanics during pelviscopic surgery
}

\author{
Min Kyo Suh, Kyu Wan Seong, Sung Hwan Jung, and Seong Su Kim \\ Department of Anesthesiology and Pain Medicine, Gangneung Asan Hospital, University of Ulsan College of Medicine, Gangneung, Korea
}

Background: Conventional pelviscopic surgery requires pneumoperitoneum with $\mathrm{CO}_{2}$ gas insufflation and lithotomy-Trendelenburg position. Pneumoperitoneum and Trendelenburg position may influence intraoperative respiratory mechanics in anesthetic management. This study was conducted to investigate the influence of pneumoperitoneum and Trendelenburg position on respiratory compliance and ventilation pressure.

Methods: Twenty-five patients scheduled for elective gynecologic laparoscopy were evaluated. The patients had no preexisting lung or heart disease or pathologic lung function. Conventional general anesthesia with thiopental sodium, lidocaine, rocuronium, and sevoflurane was administered. The peak inspiratory pressure, plateau pressure, and end-tidal $\mathrm{CO}_{2}$ were measured before and after creation of pneumoperitoneum with an intraabdominal pressure of $12 \mathrm{mmHg}$, then after 10 minutes and 30 minutes in the $20^{\circ}$ Trendelenburg position, and after deflation of pneumoperitoneum. The dynamic lung compliance was then calculated.

Results: Following creation of pneumoperitoneum, there was a significant increase in peak inspiratory pressure (6 $\mathrm{cmH}_{2} \mathrm{O}$ ), plateau pressure $\left(7 \mathrm{cmH}_{2} \mathrm{O}\right)$, and end-tidal $\mathrm{CO}_{2}(5 \mathrm{mmHg})$, while dynamic lung compliance decreased by 12 $\mathrm{ml} / \mathrm{cmH}_{2} \mathrm{O}$. Overall, the Trendelenburg position induced no significant hemodynamic or pulmonary changes.

Conclusions: The effects of pneumoperitoneum significantly reduced dynamic lung compliance and increased peak inspiratory and plateau pressures. The Tredelenburg position did not change these parameters. (Korean J Anesthesiol 2010; 59: 329-334)

Key Words: Airway pressure, Head-down tilt, Lung compliance, Pelviscopy, Pneumoperitoneum.

Received: March 31, 2010. Revised: 1st, April 14, 2010; 2nd, May 11, 2010. Accepted: June 25, 2010.

Corresponding author: Seong Su Kim, M.D., Department of Anesthesiology and Pain Medicine, Gangneung Asan Hospital, University of Ulsan College of Medicine, 415, Bangdong-ri, Sacheon-myeon, Gangneung 210-711, Korea. Tel: 82-33-610-3402, Fax: 82-33-641-8180, E-mail: sskim@gnah.co.kr The results from this study has been presented at 86th Annual Scientific Meeting of The Korean Scoiety of Anesthesiologists, Nov. 2009, Jeju.

(c) This is an open-access article distributed under the terms of the Creative Commons Attribution Non-Commercial License (http:// creativecommons.org/licenses/by-nc/3.0/), which permits unrestricted non-commercial use, distribution, and reproduction in any medium, provided the original work is properly cited. 


\section{Introduction}

Laparoscopic surgery is a minimally invasive technique with a wide range of clinical applications that has been demonstrated to be safe [1]. Advantages of laparoscopic techniques include rapid recovery, short hospital stay, rapid recovery to normal life, reduced operation scars, postoperative pain, and pulmonary complications. However, the increase of intra-abdominal pressure due to pneumoperitoneum, changes in position, and mechanical ventilation during laparoscopy can have an adverse effect on cardiopulmonary function [2-5]. Thus, anesthesiologists are required to choose rapid and safe anesthetic methods and to have knowledge about the effects and complications of iatrogenic pneumoperitoneum during laparoscopy [6].

Pneumoperitoneum created by $\mathrm{CO}_{2}$ insufflation during laparoscopic surgery elevates the diaphragm and intrathoracic pressure, which in turn affects lung compliance. Additionally, changes to the lithotomy, Trendelenburg, and reverse Trendelenburg positions reduce lung compliance by altering the location of intestinal contents and diaphragm [7]. This is especially true for the Trendelenburg position during gynecologic surgery, which potenciates the effects of abdominal pressure via gravity and relaxation of the diaphragm; thereby, increasing the airway pressure and reducing the functional residual capacity, which results in further changes in the respiratory system [7]. Conversely, it has been reported that Trendelenburg during pneumoperitoneum has no effect on pulmonary dynamics [6]. Moreover, fewer studies have been conducted to evaluate the effects of pneumoperitoneum and Trendelenburg position than the effects of the reverse Trendelenburg position during laparoscopic surgery. Therefore, we evaluated the effect of pneumoperitoneum and Trendelenburg position on respiratory mechanics during pelviscopic surgery in patients with a normal body mass index (BMI) by determining the changes in peak inspiratory pressure, plateau pressure, lung compliance, and end-tidal carbon dioxide partial pressure.

\section{Materials and Methods}

This study included twenty-five patients who were scheduled to have elective gynecolologic pelviscopic surgery under general anesthesia. All patients were classified as American Society of Anesthesiologists physical status class I or II and had no underlying cardiopulmonary diseases. All patients were fully informed of the study and signed formal consent and the study was approved by the Institutional Review Board. The BMI was calculated after measuring the height and body weight of the patients. The mean age of the patients in our study was 40 years, and the BMI was 22. Patients with a BMI greater than 25 were excluded from our study.

All patients were premedicated by intramuscular injection of $2 \mathrm{mg}$ of midazolam and $0.2 \mathrm{mg}$ of glycopyrrolate 1 hour prior to induction. After the patients arrived at the operating room, routine patient monitoring devices were applied. Anesthesia was induced by intravenous thiopental sodium ( $5 \mathrm{mg} / \mathrm{kg}$ ), and endotracheal intubation using direct laryngoscopy was conducted after the patients were paralyzed by intravenous injection of lidocaine $(1.0 \mathrm{mg} / \mathrm{kg})$ and rocuronium $(0.6 \mathrm{mg} / \mathrm{kg})$. The effect of muscle relaxants was monitored using peripheral nerve stimulator (DualStim ${ }^{\circledR}$, Life-Tech Inc., Houston, TX, USA), and the adductor pollicis longus twitch height was maintained below $25 \%$ in response to train of four stimuli to ulnar nerve stimulation. Additional rocuronium $(0.15 \mathrm{mg} / \mathrm{kg})$ was administered to maintain constant muscle paralysis at 30 minute intervals and as needed.

Conversely, the influence of airway secretion and unilateral one lung ventilation was maintained by chest auscultation with intermittent muscle relaxant injection and tracheal aspiration of secretion, if needed. Anesthesia was maintained by volume controlled ventilation with $\mathrm{O}_{2}(2 \mathrm{~L} / \mathrm{min}), \mathrm{N}_{2} \mathrm{O}(2 \mathrm{~L} / \mathrm{min})$ and sevoflurane (1.5-2.0 vol\%). A semi-closed anesthesia machine with a volume controlled ventilator was set at a tidal volume of $10 \mathrm{ml} / \mathrm{kg}$ and a respiratory rate of $10 \mathrm{cycles} / \mathrm{min}$. The mean arterial pressure (MAP), heart rates, and end-tidal carbon dioxide pressure $\left(\mathrm{EtCO}_{2}\right)$ were measured continuously using patient monitoring devices. The peak inspiratory pressure (PIP) and plateau pressure were measured using an anesthesia machine attached ventilator (Fabius ${ }^{\circledR}$ GS, Drägger, Lubeck, Germany). The I : E ratio was $1: 2$ and the plateau time was $10 \%$. Dynamic lung compliance was calculated using TV/PIP.

Pneumoperitoneum was established by insufflation of carbon dioxide gas through peviscopic insufflators, and an intraabdominal pressure less than $12 \mathrm{mmHg}$ was maintained. Baseline measurements (MAP, PIP, plateau pressure, $\mathrm{EtCO}_{2}$, and TV) in the supine position were obtained at 10 minutes after the induction of anesthesia. Each measurement was obtained at 10 minutes after establishing pneumoperitoneum in the supine-lithotomy position, 10 and 30 minutes after $20^{\circ}$ in the Trendelenburg position, and 10 minutes after return to supine position and removal of carbon dioxide. Trendelenburg position was maintained at $20^{\circ}$ by checking with a protractor (SLT-100 ${ }^{\circledR}$, Tajima, Kasugai, Japan).

All values are expressed as the mean \pm SD and were analyzed using the Friedman test and rank sum test with the SPSS (version 12.0, SPSS Inc., Chicago, IL, USA). We considered a value of $\mathrm{P}<$ 0.05 to be statistically significant. 


\section{Results}

Demographic data describing the patients are shown in Table 1. The mean age was 40 years and the median BMI was $22 \mathrm{~kg} / \mathrm{m}^{2}$.

Table 1. Patient's Demographic Data

$\begin{array}{lc}\text { Age }(\mathrm{yr}) & 40 \pm 7 \\ \text { Height }(\mathrm{m}) & 1.59 \pm 5.77 \\ \text { Weight }(\mathrm{kg}) & 57.2 \pm 6.2 \\ \text { BMI }\left(\mathrm{kg} / \mathrm{m}^{2}\right) & 22 \pm 2.7 \\ \text { ASA class (I/II) } & 23 / 2 \\ \text { Op. duration (min) } & 98 \pm 37\end{array}$

All values except for ASA class are the mean \pm SD. BMI: body mass index, ASA: American Society of Anesthesiologists, Op. duration: duration of surgical procedure.

\section{A}

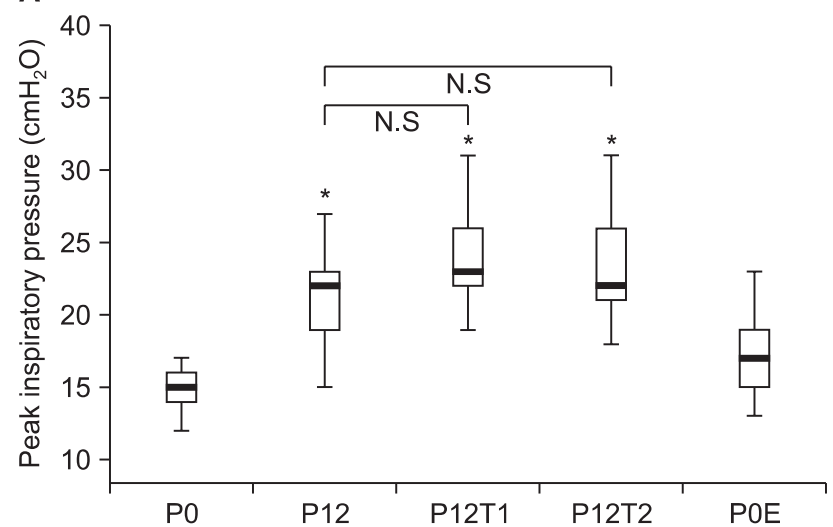

PIP and plateau pressure showed statistically significant elevation by $6 \mathrm{cmH}_{2} \mathrm{O}(\mathrm{P}<0.05)$ and $7 \mathrm{cmH}_{2} \mathrm{O}(\mathrm{P}<0.05)$ from $15.1 \pm 2.4 \mathrm{cmH}_{2} \mathrm{O}$ and $11.8 \pm 2.2 \mathrm{cmH}_{2} \mathrm{O}$ after creation of pneumoperitoneum in the supine-lithotomy position. The airway pressures were not fully returned to baseline values after removal of pneumoperitoneum and return to supine position, but this was not statistically significant. The airway pressures before and after the Tredelenburg position during pneumoperitoneum also did not differ significantly (Fig. 1).

Dynamic lung compliance showed a statistically significant decrease of $12 \mathrm{ml} / \mathrm{cmH}_{2} \mathrm{O}(\mathrm{P}<0.05)$ from $35.3 \pm 5.0 \mathrm{ml} / \mathrm{cmH}_{2} \mathrm{O}$ after creation of pneumoperitoneum in the supine-lithotomy position. Dynamic lung compliance before and after the Tredelenburg position during pneumoperitoneum did not

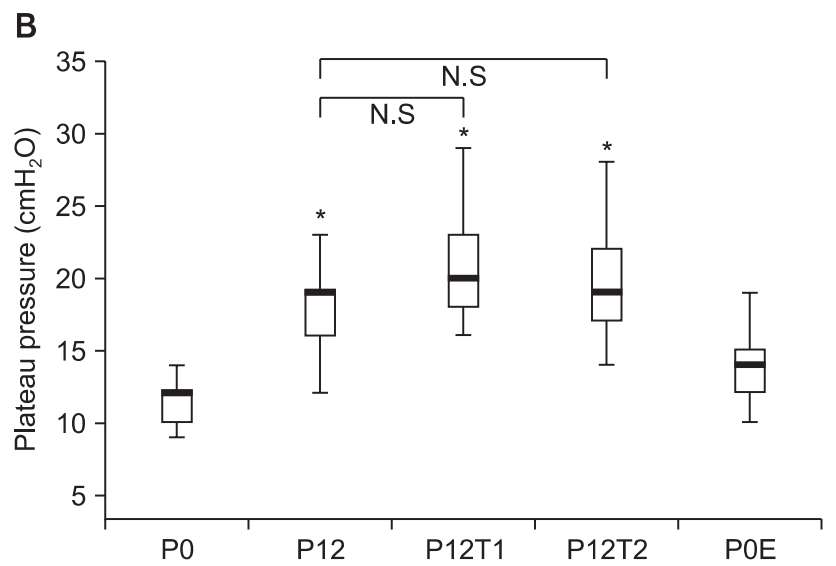

Fig. 1. Comparison of peak inspiratory (A) and plateau pressure (B) at P0, P12, P12T1, P12T2, P0E. Box and whisker plot showing median, 25th and 75th percentile, $\mathrm{T}=10$ th to 90th percentile. P0: 10 minutes after induction in the supine position, $\mathrm{P} 12: 10$ minutes after pneumoperitoneum at $12 \mathrm{mmHg}$ in the supine lithotomy position, P12T1: 10 minutes after pneumoperitoneum at $12 \mathrm{mmHg}$ and $20^{\circ}$ head-down position, P12T2: 30 minutes after pneumoperitoneum at $12 \mathrm{mmHg}$ and $20^{\circ}$ head-down position, P0E: 10 minutes after deflation in the supine position, N.S: no significance, $\mathrm{P}>0.05$ compared with $\mathrm{P} 12 . * \mathrm{P}<0.05$ compared with $\mathrm{P} 0$.

A

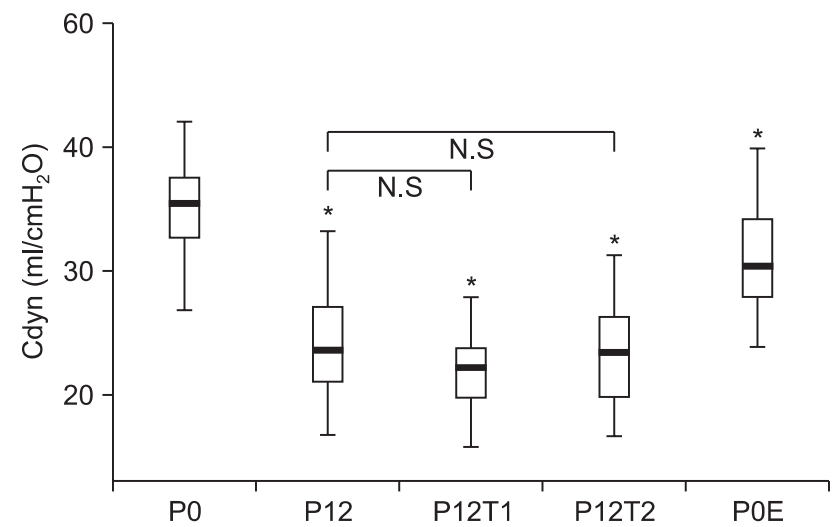

B

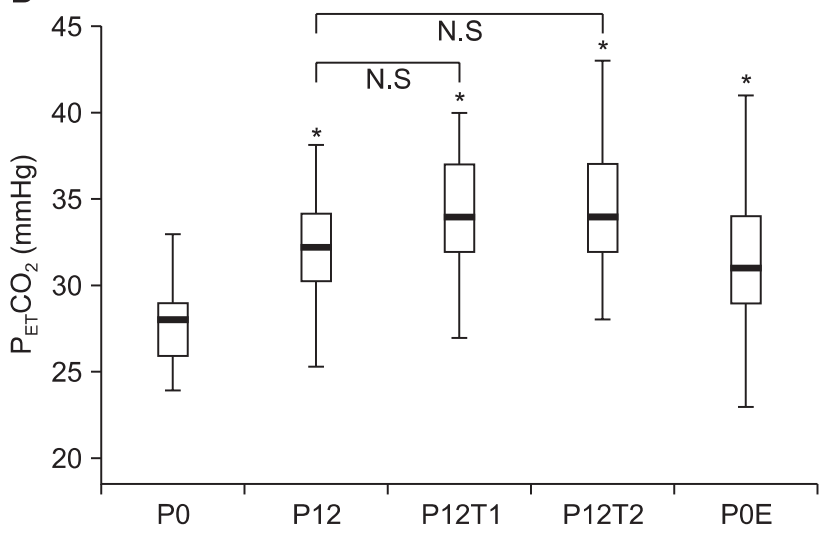

Fig. 2. Comparison of dynamic compliance (Cdyn) (A) and end-tidal $\mathrm{CO}_{2}(\mathrm{mmHg})(\mathrm{B})$ at $\mathrm{P} 0, \mathrm{P} 12, \mathrm{P} 12 \mathrm{~T} 1, \mathrm{P} 12 \mathrm{~T} 2$, P0E. Box and whisker plot showing median, 25th and 75th percentile, $\mathrm{T}=10$ th to 90 th percentile. $\mathrm{P} 0: 10$ minutes after induction in the supine position, $\mathrm{P} 12: 10$ minutes after pneumoperitoneum at $12 \mathrm{mmHg}$ in supine lithotomy position, P12T1: 10 minutes after pneumoperitoneum at $12 \mathrm{mmHg}$ and $20^{\circ}$ headdown position, P12T2: 30 minutes after pneumoperitoneum at $12 \mathrm{mmHg}$ and $20^{\circ}$ head-down position, P0E: 10 minutes after deflation in the supine position, N.S: no significance, $\mathrm{P}>0.05$ compared with P12. ${ }^{*} \mathrm{P}<0.05$ compared with $\mathrm{P} 0$. 

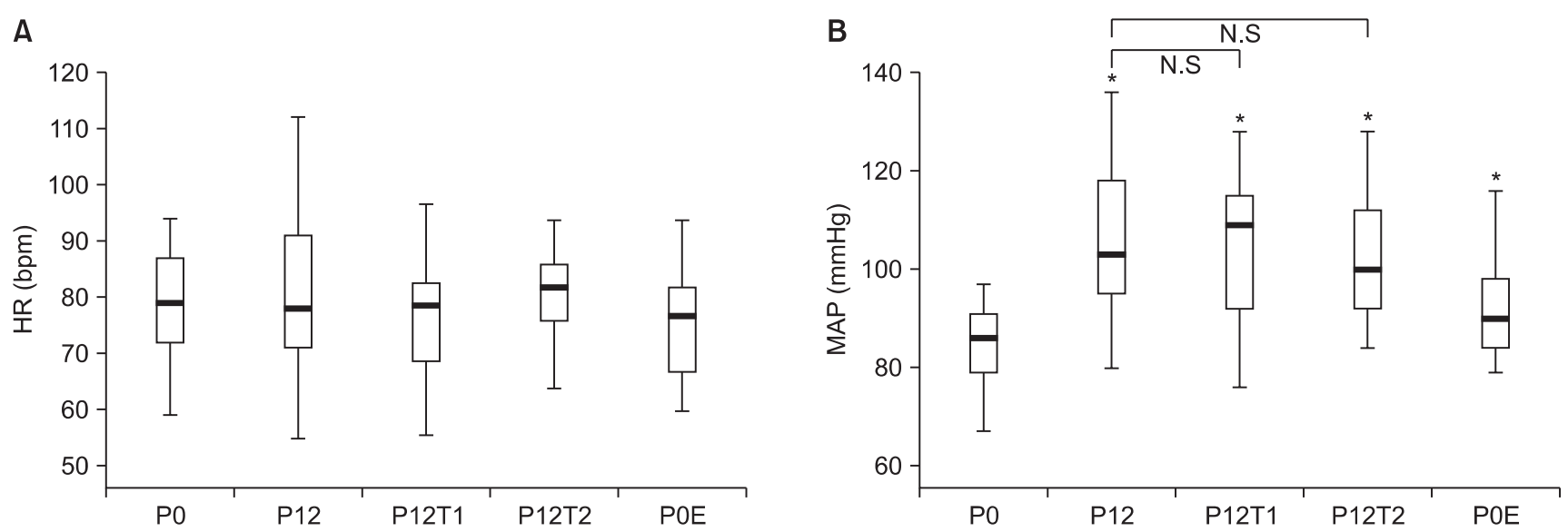

Fig. 3. Comparison of heart rates (A) and mean arterial pressure (B) at P0, P12, P12T1, P12T2, P0E. Box and whisker plot showing median, 25th and 75th percentile, $\mathrm{T}=10$ th to 90th percentile. P0: 10 minutes after induction in the supine position, P12: 10 minutes after pneumoperitoneum at $12 \mathrm{mmHg}$ in the supine lithotomy position, P12T1: 10 minutes after pneumoperitoneum at $12 \mathrm{mmHg}$ and $20^{\circ}$ head-down position, P12T2: 30 minutes after pneumoperitoneum at $12 \mathrm{mmHg}$ and $20^{\circ}$ head-down position, P0E: 10 minutes after deflation in the supine position, N.S; no significance, $\mathrm{P}>0.05$ compared with $\mathrm{P} 12 . * \mathrm{P}<0.05$ compared with $\mathrm{P} 0$.

show a statistically significant difference similar to the airway pressures. However, dynamic lung compliance following the removal of $\mathrm{CO}_{2}$ gas from the peritoneal cavity and return to the supine position decreased significantly (Fig. 2).

In the case of end-tidal carbon dioxide, measurements showed a statistically significant increase of $5 \mathrm{mmHg}(\mathrm{P}<0.05)$ from $27.7 \pm 2.3 \mathrm{mmHg} 10$ minutes after creation of pneumoperitoneum, but changing to the Tredelenburg position did not induce further changes similar to the case of dynamic lung compliance. Moreover, end-tidal carbon dioxide following the removal of $\mathrm{CO}_{2}$ gas from the peritoneal cavity and return to the supine position showed a significant increase similar to that observed in the case of dynamic lung compliance (Fig. 2).

Heart rate did not change significantly before and after creation of pneumoperitoneum and position changes from the baseline value $(79.4 \pm 9.0$ beats $/ \mathrm{min})$. In the case of blood pressure, MAP was elevated by $20 \mathrm{mmHg}$ from the baseline value $(85 \pm 10.4 \mathrm{mmHg})$ after creation of pneumoperitoneum and position change did not result in any further pressure changes. Finally, MAP after removal of $\mathrm{CO}_{2}$ gas from the peritoneal cavity and return to the supine position was higher than the baseline value (Fig. 3).

\section{Discussion}

The results of this study indicated that iatrogenic pneumoperitoneum results in decreased dynamic lung compliance and elevation of peak inspiratory pressure, plateau pressure, and end-tidal carbon dioxide tension. Although the PIP and plateau pressures returned to similar baseline values after removal of $\mathrm{CO}_{2}$ gas from the peritoneal cavity, dynamic lung compliance decreased and end-tidal carbon dioxide tension increased even after removal of the $\mathrm{CO}_{2}$ gas. These findings indicate that the Trendelenburg position may affect the peak inspiratory pressure, plateau pressure, and end-tidal carbon dioxide tension. However, Trendelenburg position did not show any effects on the respiratory system in the present study.

During gynecologic pelviscopic surgery, use of the Tredelenburg position to push the bowel out of the pelvic cavity affects cardiovascular and pulmonary function by gravity through limitation of the diaphragm movement and decreased lung inflation [8]. Vital capacity, functional residual capacity, and lung compliance are also reduced by the Tredelenburg position, and this reduction is aggravated in elderly patients and those with pre-existing pulmonary diseases $[9,10]$. Kim and Park [11] reported that the $30^{\circ}$ lithotomy-Trendelenburg position had a negative effect on hemodynamics and pulmonary function by increasing the PIP and decreasing the dynamic lung compliance significantly when compared with simple lithotomy position. In this study, the effects of position changes in patients with colorectal surgery without pneumoperitoneum were observed, but no effects of position before and after pneumoperitoneum on pulmonary function were noted. Salihoglu et al. [12] evaluated lung compliance and PIP changes after the creation of pneumopreitoneum and position change to the Tredelenburg position with pneumoperitoneum during laparoscopic cholecystectomy. Lung compliance decreased and PIP increased after creation of pneumoperitoneum, and these changes were more potentiated after position change. They concluded that the duration of pneumoperitoneum and the patient's position had significant adverse effects on pulmonary function. However, their study was conducted under pneumopreitoneum and $40^{\circ}$ Trendelenburg position while maintaining the intraabdominal pressure at $12 \mathrm{mmHg}$. The slope 
of the Trendelenburg position was greater in their study than in the present study. In our study, we maintained intraabdominal pressure at $12 \mathrm{mmHg}$ after creation of pneumoperitoneum and $20^{\circ}$ Trendelenburg position, which is a greater slope than is used in most gynecologic pelviscopic surgery. When compared to a study conducted by Salihoglu et al. [12], lung compliance decreased and PIP increased after creation of pneumoperitoneum. However, $20^{\circ}$ Trendelenburg position after pneumoperitoneum did not induce further significant changes when compared to the values after pneumopritoneum in the present study. Mäkinen and Yli-Hankala [13] reported that pneumoperitoneum with intraabdominal pressure maintained at $12 \mathrm{mmHg}$ reduced lung compliance by $35 \%$, while the Trendelenburg position reduced it by an additional $12 \%$. Thus, they concluded that pneumoperitoneum and Trendelenburg position all influenced pulmonary function. Lung compliance decreased after pneumoperitoneum and Trendelenburg position in our study; however, these decreases were not significant. Indeed, only the decrease in lung compliance in response to pneumoperitoneum was significant.

It has been reported that the BMI and creation of pneumoperitonum affected lung compliance, but that $10^{\circ}$ and $30^{\circ}$ reverse Trendelenburg or Trendelenburg position did not show further statistically significant changes $[14,15]$. Moreover, it has been reported that pneumoperitoneum led to decrease of lung compliance and increase of PIP and also the degree of pneumoperitoneum gave influence to the degree of those changes, but that $20^{\circ}$ reverse Trendelenburg or Trendelenburg position did not show further statistically significant changes [6]. Kendall et al. [16] also reported that lung compliance decreased to $49 \%$ of the baseline values after creation of $15 \mathrm{mmHg}$ pneumoperitoneum. These findings confirmed the results of the present study, which indicated that PIP and plateau pressure increased in response to intraabdominal pressure rise according to pneumoperitoneum, as well as the findings that the changes in response to the Trendelenburg position were not significant; thus, position changes did not affect respiratory dynamics. The intraabdominal pressure increase was likely due to pneumoperitoneum pushing of the diaphragm to the extent that Trendelenburg position cannot further affect respiratory dynamics. Moreover, the pneumoperitoneum is likely more important to respiratory dynamics than position changes [6]. In our study, lung compliance decreased more after removal of pneumoperitoneum than prior to pneumoperitoneum, but other studies have reported that lung compliance recovered to baseline after removal of the pneumoperitoneum $[6,14,15]$. This is likely because there was insufficient time to allow recovery of lung compliance and end-tidal carbon dioxide tension to baseline values after return to the supine position and removal of $\mathrm{CO}_{2}$ gas from the pelvic cavity. Moreover, pulmonary function changes associated with surgery cannot be excluded. Pulmonary function is affected by the types of operation, extent of intraabdominal pressure, and duration of pneumoperitoneum [6].

In conclusion, the primary factor that influences pulmonary function during gynecologic pelviscopic surgery is pneumoperitoneum, while generous Trendelenburg position change has little effect. However, overt Trendelenburg position following the creation of pneumoperitoneum can cause adverse effects on pulmonary function; therefore, more studies of this subject and other methods that can replace pneumoperitoneum are needed. Moreover, anesthesiologists should pay attention to changes in the respiratory dynamics according to pneumoperitoneum and position changes during pelviscopic surgery, and careful monitoring of cardiovascular and pulmonary function are needed to prevent postoperative pulmonary complications.

\section{References}

1. Broach AN, Mansuria SM, Sanfilippo JS. Pediatric and adolescent gynecologic laparoscopy. Clin Obstet Gynecol 2009; 52: 380-9.

2. Jakimowicz J, Stultiens G, Smulders F. Laparoscopic insufflation of the abdomen reduces portal venous flow. Surg Endosc 1998; 12: 129-32.

3. Beebe DS, McNevin MP, Crain JM, Letourneau JG, Belani KG, Abrams JA, et al. Evidence of venous stasis after abdominal insufflation for laparoscopic cholecystectomy. Surg Gynecol Obstet 1993; 176: 443-7.

4. Chiu AW, Chang LS, Birkett DH, Babayan RK. The impact of pneumoperitoneum, pneumoretroperitoneum, and gasless laparoscopy on the systemic and renal hemodynamics. J Am Coll Surg 1995; 181: 397-406.

5. Hirvonen EA, Poikolainen EO, Pääkkönen ME, Nuutinen LS. The adverse hemodynamic effects of anesthesia, head-up tilt, and carbon dioxide pneumoperitoneum during laparoscopic cholecystectomy. Surg Endosc 2000; 14: 272-7.

6. Rauh R, Hemmerling TM, Rist M, Jacobi KE. Influence of pneumoperitoneum and patient positioning on respiratory system compliance. J Clin Anesth 2001; 13: 361-5.

7. O'Malley C, Cunningham AJ. Physiologic changes during laparoscopy. Anesthesiol Clin North America 2001; 19: 1-19.

8. Foroughi V, Krucylak PE, Baudendistel LJ. Anesthesia for laparoscopy. In: Minimally Invasive Surgery: Principles and Outcomes. Edited by Andrus CH, Cosgrove JM, Longo WE: Amsterdam, Harwood Academic Publishers. 1998, pp 20-2.

9. Lee KS, Kim SY, Kim HD. Effects of intraabdominal $\mathrm{CO}_{2}$ gas insufflation on $\mathrm{PaCO}_{2}$ and tidal volume during laparoscopic surgery under general anesthesia. Korean J Anesthesiol 1992; 25: 935-40.

10. Fahy BG, Barnas GM, Nagle SE, Flowers JL, Njoku MJ, Agarwal M. Effects of Trendelenburg and reverse Trendelenburg postures on lung and chest wall mechanics. J Clin Anesth 1996; 8: 236-44.

11. Kim SY, Park SJ. The effect of the lithotomy-trendelenburg position on respiratory and hemodynamic changes during general 
anesthesia. Korean J Anesthesiol 2002; 42: 722-9.

12. Salihoglu Z, Demiroluk S, Cakmakkaya S, Gorgun E, Kose Y. Influence of the patient positioning on respiratory mechanics during pneumoperitoneum. Middle East J Anesthesiol 2002; 16: 521-8.

13. Mäkinen MT, Yli-Hankala A. The effect of laparoscopic cholecystectomy on respiratory compliance as determined by continuous spirometry. J Clin Anesth 1996; 8: 119-22.

14. Kim YB, Chang CH, Kim SY, Nam YT. Effect of BMI and patient positioning on airway pressures and respiratory compliance during laparoscopic surgery. Korean J Anesthesiol 2006; 50: 302-7.

15. Sprung J, Whalley DG, Falcone T, Warner DO, Hubmayr RD, Hammel J. The impact of morbid obesity, pneumoperitoneum, and posture on respiratory system mechanics and oxygenation during laparoscopy. Anesth Analg 2002; 94: 1345-50.

16. Kendall AP, Bhatt S, Oh TE. Pulmonary consequences of carbon dioxide insufflation for laparoscopic cholecystectomies. Anaesthesia 1995; 50: 286-9. 